\title{
DEAFNESS IN CHILDREN OF VERY LOW BIRTH WEIGHT
}

\author{
BY \\ ALISON D. McDONALD \\ From the Paediatric Research Unit, Guy's Hospital Medical School, London
}

(RECEIVED FOR PUBLICATION OCTOBER 8, 1963)

In the course of a survey of over a thousand children weighing $4 \mathrm{lb}$. $(1,800 \mathrm{~g}$.) or less at birth, there was an opportunity to investigate the occurrence of deafness in these children. This survey was made with the Society of Medical Officers of Health and was undertaken primarily to study the aetiology of cerebral palsy (McDonald, 1963). Deafness sufficient to require special schooling is very uncommon. The Ministry of Education (1946) has estimated a prevalence of 0.7 to 1 per 1,000 in children of school age; Barton, Court and Walker (1962) in a survey in Northumberland and Durham found a rate of 0.7 per 1,000: in this survey deafness was thought to be hereditary in $25 \%$, to have followed meningitis or some other infection in a further $25 \%$, but in $50 \%$ of children the cause was unknown. Rubella in early pregnancy and severe haemolytic disease of the newborn each accounted for less than $1 \%$ of the total. Among the cases of unexplained deafness, $7 \cdot 6 \%$ of the children had a birth weight of less than $4 \mathrm{lb}$. $(1,800 \mathrm{~g}$.), which may be compared with approximately $0.4 \%$ in the general population (Gibson and McKeown, 1951).

Several surveys have shown that children weighing not more than $5 \frac{1}{2} \mathrm{lb}$. $(2,500 \mathrm{~g}$. $)$ at birth have a higher rate of deafness than those weighing over $5 \frac{1}{2} \mathrm{lb}$. (Johnsen, 1952; Fisch and Osborn, 1954; McDonald, 1962b). Drillien (1961), in a study of 50 children aged 5 years who had weighed $3 \mathrm{lb}$. $(1,400 \mathrm{~g}$.) or less at birth, found $5(10 \%)$ with hearing defects.

The audiograms of premature children with perceptive deafness were found by Fisch and Osborn to be similar to those of children who had kernikterus in infancy, and to those of children with a history of asphyxia at birth. Characteristically the audiograms showed moderate or severe high frequency loss with never more than moderate low frequency loss. Campanelli, Pollock and Henner (1958), in a study of 44 children aged 6 years who had been admitted to a premature baby nursery, found high frequency deafness in $7(16 \%) ; 44$ children weighing over $5 \frac{1}{2} \mathrm{lb}$. $(2,500 \mathrm{~g}$.) at birth had normal hearing. The 7 deaf children were lighter than the
37 who were not deaf (mean weight, 981 g., compared with $1,718 \mathrm{~g}$.), and they had a much shorter mean gestation period $(26 \cdot 3$ weeks compared with 33 weeks). The deaf children were kept in an incubator for an average of 24 days compared with 8 days for those who were not deaf, but it was thought improbable that excessive oxygen administration was responsible for the deafness because no association between retrolental fibroplasia and deafness has been observed.

Fraser (1962) suggested that the association between prematurity and deafness might be due to streptomycin. Premature infants are frequently given streptomycin and may be more sensitive to it than adults.

Pathological evidence on the nature of lesions causing perceptive deafness is scanty. Dublin (1951) and Gerrard (1952) reported destruction of nerve cells in the cochlear nuclei at autopsy in kernikterus; but in none of the cases had hearing been tested. Haymaker, Margoles, Pentschew, Jacob, Lindenberg, Arroyo, Stochdorph and Stowens (1961) found only slight gliosis in the cochlear nuclei of two children with post-kernikteric encephalopathy. who were known to have been deaf.

\section{Materials and Methods}

The methods used in the survey and the clinical findings have already been described (McDonald, 1962a). Of 1,128 children weighing $4 \mathrm{lb} .(1,800 \mathrm{~g}$.) or less at birth and alive at the age of 6 months, 1,081 were traced when they were from 6 to 8 years old; 28 had died and 19 could not be traced. All children reported deaf by health visitors were further investigated, and whenever possible copies of audiograms were obtained. Of the children in the sample $19(1.8 \%)$ were found to be suffering from perceptive deafness of a moderate or severe degree, and 2 of them had bilateral athetosis, one had spastic monoplegia affecting a lower limb and another had retrolental fibroplasia; no serious physical defects were found in the remaining 15 . One of the deaf children was a twin and the others were single infants; the difference between the rate of $0.3 \%$ in multiple births and $2.4 \%$ in single births was significant at a $5 \%$ level. 


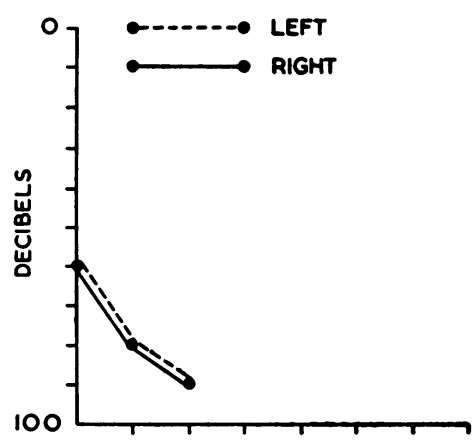

FIG.-Audiograms taken for routine purposes for 10 of the 17 deaf children without athetoid cerebral palsy.
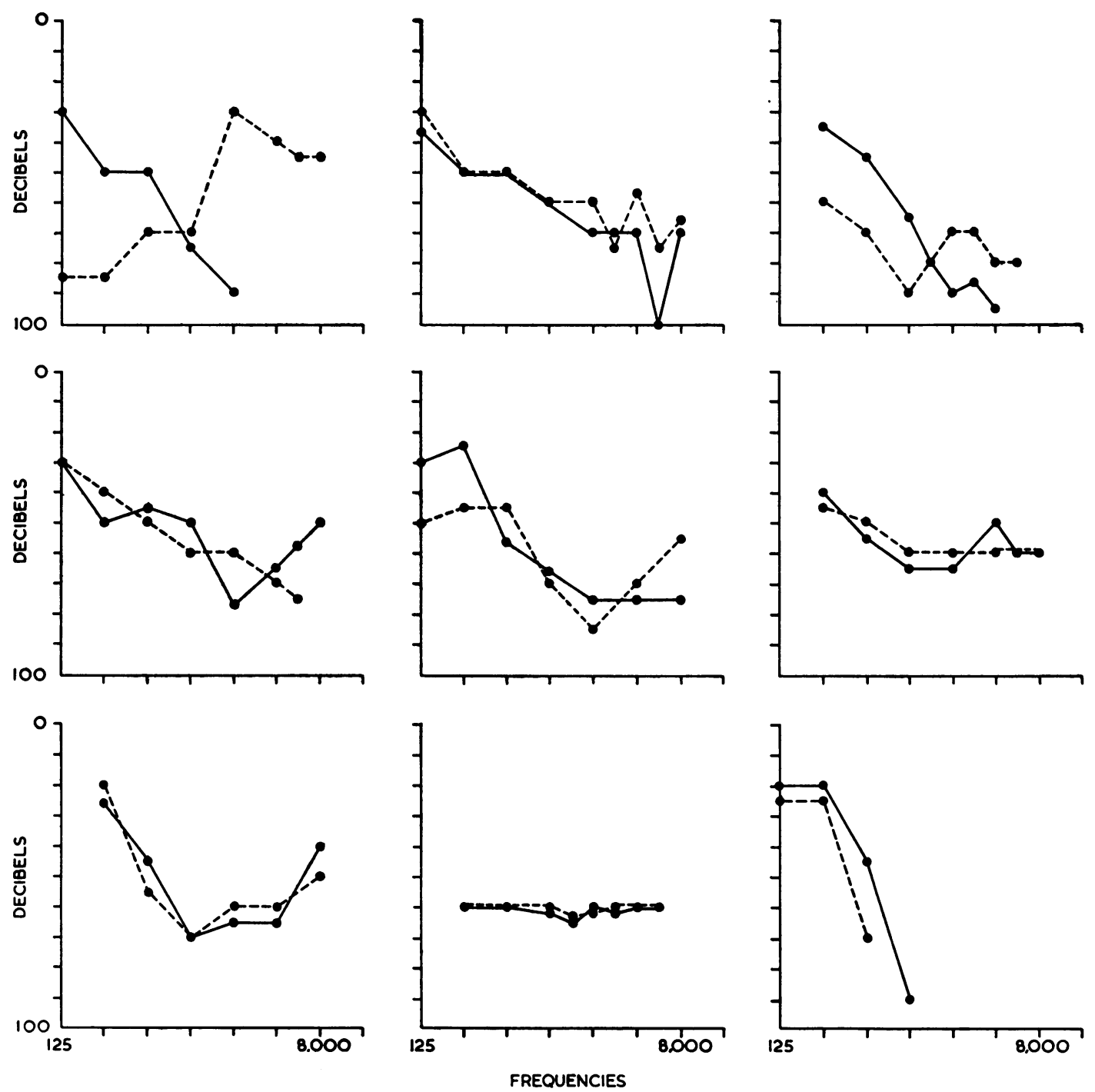
TABLE 1

DEAFNESS IN SINGLE CHILDREN ACCORDING TO BIRTH WEIGHT AND LENGTH OF GESTATION

\begin{tabular}{|c|c|c|c|c|c|c|c|c|c|c|}
\hline \multirow{3}{*}{ Birth Weight } & \multicolumn{10}{|c|}{ Length of Gestation (weeks) } \\
\hline & \multicolumn{2}{|c|}{-30} & \multicolumn{2}{|c|}{$31-2$} & \multicolumn{2}{|c|}{$33-4$} & \multicolumn{2}{|c|}{$35+$} & \multicolumn{2}{|c|}{ All } \\
\hline & At Risk & Rate $\%$ & At Risk & Rate $\%$ & At Risk & Rate $\%$ & At Risk & Rate $\%$ & At Risk & Rate $\%$ \\
\hline $\begin{array}{l}3 \mathrm{lb} . \text { or less } \\
3 \mathrm{lb} .1 \text { oz.- }\end{array}$ & 101 & $3 \cdot 0$ & 36 & $8 \cdot 3$ & 21 & $4 \cdot 8$ & 14 & 0 & 181 & $3 \cdot 5$ \\
\hline $\begin{array}{l}3 \text { lb. } 8 \text { oz. } \\
3 \text { lb. } 9 \text { oz. }-4 \text { lb. }\end{array}$ & $\begin{array}{l}54 \\
39\end{array}$ & $\begin{array}{r}3 \cdot 7 \\
10 \cdot 3\end{array}$ & $\begin{array}{l}59 \\
98\end{array}$ & $\begin{array}{l}1 \cdot 7 \\
3 \cdot 1\end{array}$ & $\begin{array}{l}44 \\
95\end{array}$ & $\begin{array}{l}0 \\
0\end{array}$ & $\begin{array}{r}48 \\
117\end{array}$ & $\begin{array}{l}0 \\
0.9\end{array}$ & $\begin{array}{l}212 \\
366\end{array}$ & $\begin{array}{l}2 \cdot 0 \\
2 \cdot 3\end{array}$ \\
\hline All & 194 & $4 \cdot 6$ & 193 & $3 \cdot 6$ & 160 & 0.6 & 179 & 0.6 & $759^{*}$ & $2 \cdot 4$ \\
\hline
\end{tabular}

* Including 33 children with an unknown length of gestation.

TABLE 2

DEAFNESS IN SINGLE CHILDREN ACCORDING TO PRENATAL AND PERINATAL FACTORS AND LENGTH OF GESTATION

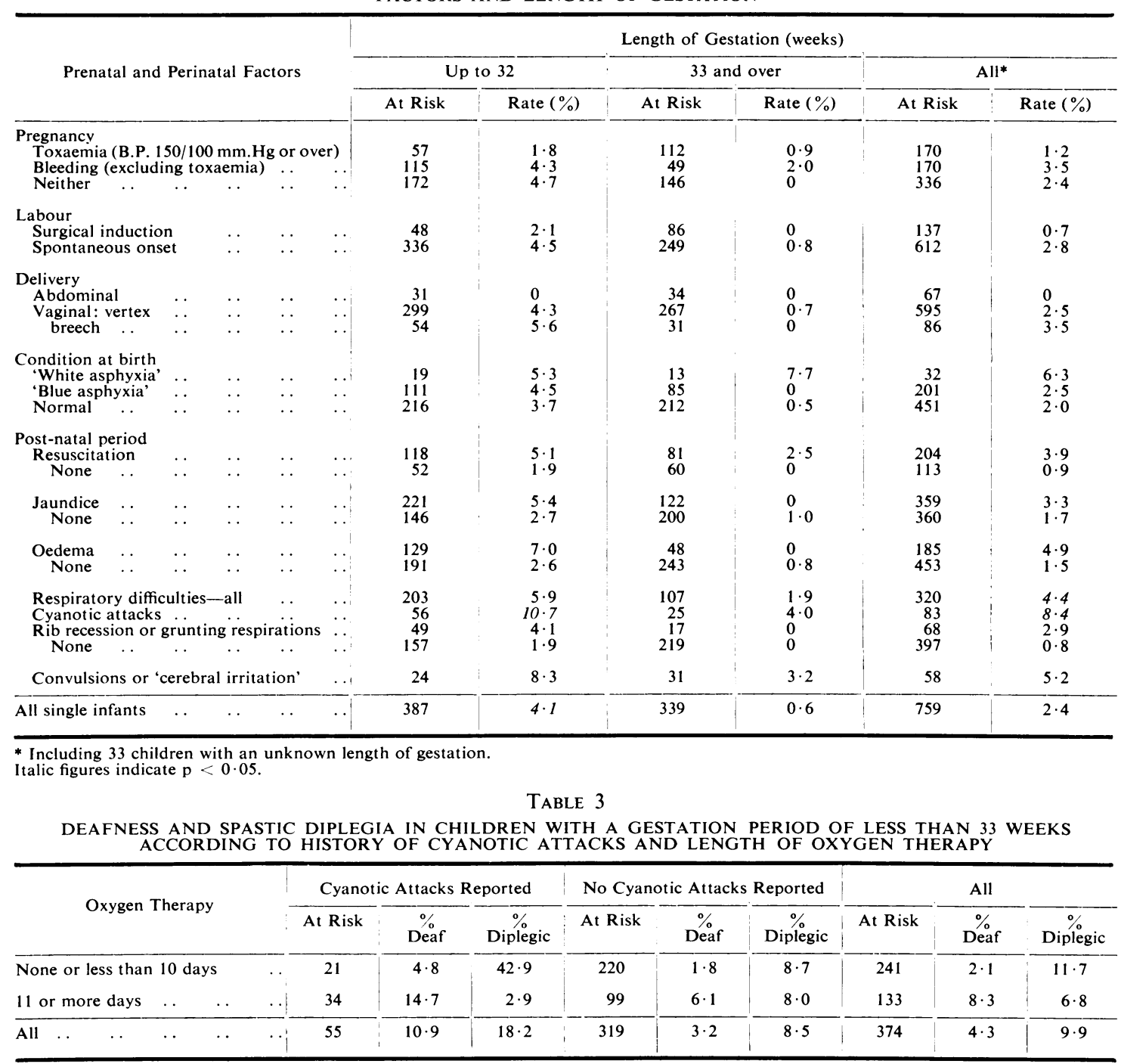


The 2 children with bilateral athetosis were at a school for cerebral palsy, one child whose educability was in doubt was attending an occupation centre, 3 were able with the help of hearing aids to attend primary schools, and the remaining 13 were at schools for the deaf. Copies of audiograms taken for routine purposes at diagnostic centres or special schools were obtained for 10 of the 17 children without bilateral athetosis (Fig.). The majority showed slight to moderate low frequency hearing loss and moderate to severe high frequency loss.

No case of familial deafness was reported, but as special inquiries were not made, this could not be excluded. None of the cases was attributable to rubella in early pregnancy. Two children in the whole sample had such a history; one was normal and the other had cataracts, but was not deaf, and died of congenital heart disease.

\section{Findings}

Because of the low rate of deafness in multiple births, the analysis of the findings was restricted to single births. There were too few deaf children to reveal any but grossly abnormal distributions of maternal age, parity or social class, and no statistically significant differences were observed.

Length of Pregnancy and Birth Weight. Of 387 single children with a gestation period of less than 33 weeks, $16(4 \cdot 1 \%)$ were deaf (Table 1), compared with only $2(0.6 \%)$ of 339 single children with a gestation period of 33 or more weeks $(p=0.003)$. There was no association with birth weight other than that attributable to gestational age; this was confirmed in a statistical analysis by Dr. C. C. Spicer, described in the Appendix.

Prenatal and Perinatal History. Because of the evident importance of length of gestation, prenatal and perinatal variables were examined according to this factor (Table 2). As there were few deaf children, only fairly definite associations could be expected to show themselves. At less than 33 weeks' gestation, $10.7 \%$ of 56 children with a history of cyanotic attacks were deaf compared with $3.0 \%$ of the remaining 331 children $(p=0.02)$. In the analysis described in the Appendix, children with cyanotic attacks were grouped with those with signs of the respiratory distress syndrome, since both conditions were likely to give rise to oxygen deprivation in the neonatal period. A significant association was found with these signs which was independent of duration of gestation.

No significant differences were found in the rate of deafness in either of the two gestation groups in Table 2 according to the following factors: a maternal history of bleeding or toxaemia, induction of labour, presentation or asphyxia on delivery.
This was shown by the absence of any significant difference between expected numbers of children calculated by the method described in the Appendix and the numbers observed.

Rates of deafness were higher at less than 33 weeks' gestation in children with a history of jaundice or generalized oedema than in those without such a history. There was also a slightly increased rate of deafness in children with convulsions in the neonatal period. None of these differences was however significant at a $5 \%$ level and no significant differences were found between observed and expected numbers of children when length of gestation and cyanotic attacks or respiratory distress were taken into account.

Oxygen and Antibiotic Treatment. A higher rate of deafness was found in children given oxygen for more than 10 days (Table 3 ), than in those given oxygen for a shorter time $(p=0.01)$; this difference was present both in children who had cyanotic attacks and in those who did not. A higher rate of deafness was also found in children given antibiotics, especially streptomycin, than in those not given antibiotics. Among children with a gestation period of less than 33 weeks the rates of deafness were $10.7 \%$ in 75 children given streptomycin, $5.8 \%$ in 120 children given other antibiotics and only $0.6 \%$ in 157 children not given any antibiotic.

The use of oxygen and antibiotics is closely related to the clinical condition of the infant and particularly to respiratory signs. Allowing for the relation between cyanotic attacks or respiratory distress and deafness, expected numbers of deaf children were calculated according to whether an antibiotic was given and the duration of oxygen treatment (Table 4). An excess of deafness was found in children who were given streptomycin and were kept in oxygen for more than 10 days, and a deficiency among children who were not given any antibiotic and who had oxygen for less than 10 days.

In Table 5 the centres were divided into three groups according to the median length of oxygen administration to children of less than 33 weeks' gestation. There was little difference between the centres in the proportion of children weighing $3 \mathrm{lb}$. or less and the proportion with a gestation period of under 31 weeks. The rates of deafness were similar in all three groups, whereas there was less spastic diplegia in the group given oxygen longest $(p=0.06)$ and more retrolental fibroplasia $(\mathrm{p}=0 \cdot 11)$.

An attempt was made to compare the dose and duration of streptomycin treatment given to deaf children and to those who were not deaf. The necessary information was unfortunately missing in 
TABLE 4

DEAFNESS ACCORDING TO OXYGEN AND ANTIBIOTIC THERAPY IN CHILDREN WITH A GESTATION PERIOD OF LESS THAN 33 WEEKS ALLOWING FOR THE EFFECT OF CYANOTIC ATTACKS

\begin{tabular}{|c|c|c|c|c|c|c|c|c|c|c|}
\hline & & & & & \multicolumn{4}{|c|}{ Oxygen } & & \\
\hline \multirow{2}{*}{\multicolumn{5}{|c|}{ Antibiotics }} & \multicolumn{2}{|c|}{ Up to 10 Days } & \multicolumn{2}{|c|}{11 or More Days } & \multicolumn{2}{|c|}{ All } \\
\hline & & & & & Expected & Observed & Expected & Observed & Expected & Observed \\
\hline Streptomycin & . & $\cdots$ & . & $\ldots$ & $2 \cdot 391$ & 3 & $1 \cdot 556$ & 7 & $3 \cdot 947$ & 10 \\
\hline Other antibiotics & . & $\cdots$ & . & $\cdots$ & $3 \cdot 712$ & 3 & $2 \cdot 844$ & 4 & $6 \cdot 556$ & 7 \\
\hline No antibiotics & $\cdots$ & $\cdots$ & $\cdots$ & $\cdots$ & $5 \cdot 148$ & 0 & $2 \cdot 190$ & 1 & $7 \cdot 339$ & 1 \\
\hline All & $\cdots$ & $\cdots$ & $\cdots$ & $\cdots$ & $11 \cdot 251$ & 6 & $6 \cdot 590$ & 12 & $17 \cdot 842$ & 18 \\
\hline
\end{tabular}

about half the cases, but of 5 deaf children with a gestational age of less than 33 weeks the mean total dose per child was $113 \mathrm{mg}$. and the mean duration of treatment four days, compared with $370 \mathrm{mg}$. and four days in 31 children who were not deaf.

\section{Discussion}

Most of the deafness in this series of premature infants occurred in those with a gestational age of less than 33 weeks; this readily explains previous observations of a high rate of deafness among children of very low birth weight. Among very immature children, those who had cyanotic attacks in the first few weeks of life, probably involving periods of anoxia, had the highest prevalence of deafness. This seems to be most simply explained by a hypothesis of selective anoxic damage to the cochlear nuclei occurring during early postnatal life. Since there was no association between deafness and asphyxia immediately after birth, it seems unlikely that deafness was attributable to intrapartum asphyxia.

In spite of the fact that the sample included two children with double athetosis and deafness following kernikterus, no association with jaundice was found. This suggests that jaundice cannot be held responsible for more than a small proportion of the deafness in very small infants.

The association with streptomycin treatment raises the possibility that premature infants may be particularly susceptible to this drug. The association was possibly an indirect one, however, due to the fact that infants in a poor general condition, and particularly those with respiratory difficulties, tended to be given streptomycin. Points in support of this explanation are as follow: (1) Children given no antibiotics had substantially less deafness than children given antibiotics other than streptomycin. (2) The excess of deafness was only in children given oxygen for more than 10 days. (3) No dosage effect was detected. (4) Since streptomycin was only given to 10 of the 19 deaf children, it could not be held responsible for deafness in the other 9. Thus, although it is impossible to say that streptomycin did not cause deafness, it was more probably a question of the children to whom it was given.

TABLE 5

SPASTIC DIPLEGIA, DEAFNESS AND RETROLENTAL FIBROPLASIA IN CHILDREN WITH A GESTATION PERIOD OF LESS THAN 33 WEEKS, ACCORDING TO PRACTICE OF OXYGEN ADMINISTRATION IN PREMATURE BABY UNIT

\begin{tabular}{|c|c|c|c|c|c|c|c|}
\hline Centre & $\begin{array}{c}\text { Median } \\
\text { Duration of } \\
\text { Oxygen Therapy } \\
\text { (days) }\end{array}$ & $\begin{array}{c}\text { Total } \\
\text { Number of } \\
\text { Children }\end{array}$ & $\begin{array}{c}\% \\
\text { With } \\
\text { Gestation Less } \\
\text { than } 31 \text { Weeks }\end{array}$ & $\begin{array}{c}\text { \% } \\
\text { With } \\
\text { Birth Weight } \\
3 \text { lb. or Less }\end{array}$ & $\begin{array}{c}\% \\
\text { With } \\
\text { Spastic } \\
\text { Diplegia }\end{array}$ & $\begin{array}{c}\text { \% } \\
\text { Deafness }\end{array}$ & $\begin{array}{c}\text { With } \\
\text { Retrolental } \\
\text { Fibroplasia }\end{array}$ \\
\hline $\begin{array}{r}7 \\
12 \\
11 \\
14\end{array}$ & $\left.\begin{array}{l}0 \\
0 \\
1 \\
1\end{array}\right\}$ & 51 & 45 & 39 & $11 \cdot 8$ & 3.9 & 3.9 \\
\hline $\begin{array}{l}2 \\
8 \\
9 \\
3\end{array}$ & $\left.\begin{array}{l}5 \\
6 \\
6 \\
8\end{array}\right\}$ & 207 & 49 & 33 & $12 \cdot 1$ & $3 \cdot 9$ & $7 \cdot 7$ \\
\hline $\begin{array}{r}1 \\
10 \\
5 \\
13 \\
6 \\
4\end{array}$ & $\left.\begin{array}{l}10 \\
10 \\
14 \\
14 \\
15 \\
17\end{array}\right\}$ & 129 & 53 & 37 & $5 \cdot 4$ & $4 \cdot 7$ & $12 \cdot 4$ \\
\hline
\end{tabular}


The same sort of argument can be applied to the findings on oxygen therapy. There was no evidence of an association with prolonged oxygen therapy among children given antibiotics other than streptomycin, and since children with the greatest amount of cyanosis were likely to have been kept longest in oxygen this seems the most probable explanation for the association.

The rates of both spastic diplegia and deafness were significantly raised in children with a short gestation period, in single compared with multiple births and in children with cyanotic attacks compared with those without. The rate of diplegia was nearly two and a half times as high as the rate of deafness, and although both disorders tended to be commoner in children who were jaundiced or oedematous, the only significant association was between jaundice and diplegia. Diplegia and deafness occurred in children similar in these respects, but there was no tendency for the disorders to occur in the same children. Whereas deafness was associated with longer periods of oxygen administration the reverse was true of diplegia; it seems probable that the clinical condition of the deaf children may therefore have been worse than that of the diplegic children.

It is suggested that asphyxia during the neonatal period is responsible for deafness in very immature infants, and that the mechanism is neuronal damage by hypoxia.

\section{Summary}

Of 1,081 surviving children with a birth weight of $4 \mathrm{lb}$. or less, $19(1 \cdot 8 \%)$ were found to have perceptive deafness of a moderate or severe degree; 2 had athetoid cerebral palsy and 1 spastic monoplegia affecting a lower limb. No motor disorder was present in the remainder. Moderate to severe high-frequency hearing loss with little loss at low frequencies was the commonest type of deafness found.

Only one case of deafness occurred in a twin; this represented a prevalence of $0.3 \%$. In single children with gestations lasting at least 33 weeks the prevalence was $0.6 \%$ but in those with shorter periods of gestation it was $4.1 \%$. In these very immature children deafness was significantly associated with cyanotic attacks in the first few weeks of life. Although the two children with athetoid cerebral palsy had severe jaundice, deafness was not significantly related to jaundice. Associations with both streptomycin therapy and prolonged oxygen administration were probably due to these treatments being given to the children whose clinical condition was worst.
It is concluded that anoxia in the early postnatal life of very immature infants may cause deafness.

I am grateful to the Medical Research Council for permission to use their detailed birth records, to Principal School Medical Officers for carrying out the survey of the children and to Dr. C. C. Spicer for statistical help.

I am indebted to Miss $\mathrm{H}$. Wood for doing part of the analysis and to Miss D. Baker for the diagram.

\section{REFERENCES}

Barton, M. E., Court, S. D. and Walker, W. (1962). Causes of severe deafness in schoolchildren in Northumberland and Durham. Brit. med. J., 1, 351.

Campanelli, P. A., Pollock, F. J. and Henner, R. (1958). An otoaudiological evaluation of forty-four premature children. Arch. Otolaryng., 67, 609.

Drillien, C. M. (1961). The incidence of mental and physical handicaps in school-age children of very low birth weight. Pediatrics, $27,452$.

Dublin, W. B. (1951). Neurologic lesions of erythroblastosis fetalis in relation to nuclear deafness. Amer. J. clin. Path., 21, 935 .

Fisch, L. and Osborn, D. A. (1954). Congenital deafness and haemolytic disease of the newborn. Arch. Dis. Childh., 29, 309.

Fraser, G. R. (1962). Streptomycin as a cause of congenital deafness Develop. Med. Child Neurol., 4, 219.

Gerrard, J. (1952). Nuclear jaundice and deafness. J. Laryng., 66, 39.

Gibson, J. R. and McKeown, T. (1951). Observations on all births $(23,970)$ in Birmingham, 1947. III. Survival. Brit. J. soc. Med., 5, 177.

Haymaker, W., Margoles, C., Pentschew, A., Jacob, H., Lindenberg, R., Arroyo, L. S., Stochdorph, O. and Stowens, D. (1961) Pathology of Kernicterus and posticteric encephalopathy. In Kernicterus and its Importance in Cerebral Palsy: A Conference presented by the American Academy for Cerebral Palsy (Eleventh Annual Meeting, New Orleans). Thomas, Springfield, Illinois.

Johnsen, S. (1952). Natal causes of perceptive deafness. Acta oto-laryng. (Stockh.), 42, 51.

McDonald, A. D. (1962a). Neurological and ophthalmic disorders in children of very low birth weight. A survey with the Society of Medical Officers of Health. Brit. med. J., 1, 895.

(1962b). Congenital defects associated with prematurity. Arch. Dis. Childh., 37, 277.

- (1963). Cerebral palsy in children of very low birth weight. ibid., 38, 579.

Ministry of Education (1946). Special Educational Treatment. Pamphlet No. 5. H.M.S.O., London.

\section{Appendix}

Statistical Note by C. C. Spicer

Using a technique which $I$ described in a previous statistical appendix (McDonald, 1963), tables of proportions were transformed to a logit scale and constants fitted by least squares, using weights and working logits, for the following factors: gestation period; birth weight; presence or absence of jaundice; presence or absence of cyanotic attacks or respiratory distress. It was found that there was no relation between deafness and either birth weight or history of jaundice when gestation was taken into account, and these were dropped from the analysis. The constants for the factors fitted in this way together with their standard errors were: gestation (mean term), $0.155 \pm 0.0656$; cyanotic attacks or respiratory distress, $0 \cdot 564 \pm 0 \cdot 245$; and $\chi^{2}, 5 \cdot 48$ (5 D.F.).

Length of gestation and cyanotic attacks or respiratory distress were associated with deafness since both the relevant constants exceeded twice their standard error.

The effect of other factors was studied by calculating expected numbers, using the constants fitted previously. 